\title{
AN UNUSUAL INJURY FROM TOOTHBRUSH: A CASE REPORT
}

\author{
Deepak Yadav ${ }^{1}$, Shashank Tripathi ${ }^{1}$, Ravish Mishra ${ }^{1}$, Laxmi Kandel ${ }^{1}$, Saurav Karna ${ }^{2}$, Santosh Kandel ${ }^{3}$
}

\section{ABSTRACT}

Toothbrush plays a vital role in the maintenance of oral health and dental hygiene. Regular brushing is widely advocated by dental surgeon in terms of decreasing dental caries and periodontal problems. Though, there has been decrease in diseases due to sequale of poor oral hygiene, at the same time there are also inherent risk of accidental trauma to the surrounding soft tissue during the act of brushing, more commonly when handled by children. This paper presents a case report of a penetrating toothbrush trauma embedded in buccal soft tissue which required surgical intervention in a child patient.

KEY WORDS tooth brush, trauma, surgical intervention.

1. Lecturer, Department of Oral and Maxillofacial Surgery, Universal College of Medical Sciences, Bhiarawa, Nepal

2. Oral and Maxillofacial Surgeon, Chief Clinical and Outreach program Craniofacial Center Nepal Janakpurdham Nepal

3. Lecturer, Department of Dental Surgery, Lumbini Medical College, Palpa, Nepal

For Correspondence

Dr. Deepak Yadav

Lecturer

Department of Oral and Maxillofacial Surgery

Universal College of Medical Sciences

Bhairahawa, Nepal

Email:dr_deepakydv@yahoo.com 


\section{INTRODUCTION}

Toothbrush plays a vital role in maintenance of oral health and dental hygiene and regular brushing is widely advocated by dental surgeon in terms of decreasing dental caries and periodontal problems. Though there has been decrease in diseases due to sequale of poor oral hygiene, at the same time there are also inherent risk of accidental trauma to the surrounding soft tissue during the act of brushing, more commonly when handled by children.

This paper presents a case report of a penetrating toothbrush trauma embedded in buccal soft tissue which required surgical intervention in a child patient.

\section{CASE REPORT}

A 2-year old male child was referred to the department of Oral and Maxillofacial Surgery regarding a penetrating injury sustained at home as shown in figure 1. The child experienced a hit by goat at home while he was running with a toothbrush in his mouth and hit his face against the floor. This caused the bristle portion of the brush to be embedded in the buccal soft tissue. The patient was quiet without any obvious distress, with the handle of the toothbrush projecting horizontally from the mouth. All the vital signs were under normal range and the medical history was not significant. There was no active bleeding but mild drooling of the saliva from the corner of the mouth was present. Extraorally there was a presence of buldge at angle of mandible and below the ear lobule on the left side, which was tender on palpation as shown in figure 2. Patient was then advised for Plain X-Ray; P.A view mandible but couldn't delineate the position of toothbrush. Initially gentle force was used by the guardian of patient to remove the tooth brush, but there was excruciating pain. Owing to this information and the patient's age, general anesthesia was selected to remove the toothbrush.

Before we could proceed with general anesthesia, local anesthesia was infiltrated around the buldge and a small linear incision was made owing to removal of bristle without resistance as shown in figure 3. After that gentle push was given so as to remove toothbrush from extraoral region. The wound was then thoroughly irrigated with normal saline and betadine and suture were placed both extra orally and intra orally. The patient was admitted for 2 days with intravenous antibiotics and analgesics. The patient was then discharged with oral antibiotics, subsequently followed up for a week. Wound healing was satisfactory with no any complications.

\section{DISCUSSION:}

This case report highlights the rare occurrence of penetrating toothbrush injury in a child. Toothbrush-related penetrating injuries have been reported previously involving intra oral penetration $^{1,2}$. Toothbrush bristles have also been reported in the maxillary sinus in a paediatric patient due to self-inflicted injury $^{3}$. Law et al described two cases of children less than 3 years with toothbrush trauma, causing injury to soft palate and anterior faucial pillar, the soft palate injury progressed to mediastinitisand the anterior faucial pillar injury progressed to retropharyngeal abscess ${ }^{4}$. The penetrating injuries can produce various complications, hence the patient should be examined for ${ }^{1,45}$

a. Airway and breathing problems

b. Bleeding from mucosa or lacerations

c. Neurological deficit such as change in mental status d. Signs of acute infection such as swelling, pyrexia etc

Patient with any of these features should be managed accordingly. If these symptoms are not apparent, the embedded toothbrush can be removed either in local anesthesia or general anesthesia depending upon patient condition like age, medical history, etc. ${ }^{1,5}$ After the incision, the toothbrush was gently manipulated so as to avoid the chances of bleeding from vessels ${ }^{6}$. The bristle was dissected and was removed along the path where there was a least resistance from bristle.

After removal of toothbrush hemostasis should be evaluated as the bleeding may result in hematoma in deeper planes which could be fatal at times

Suturing of the wound should be done. Antibiotics should be prescribed along with a dose of tetanus toxoid and after discharge the patient should be reviewed on timely basis as the complication can manifest after a period of 72 hours.

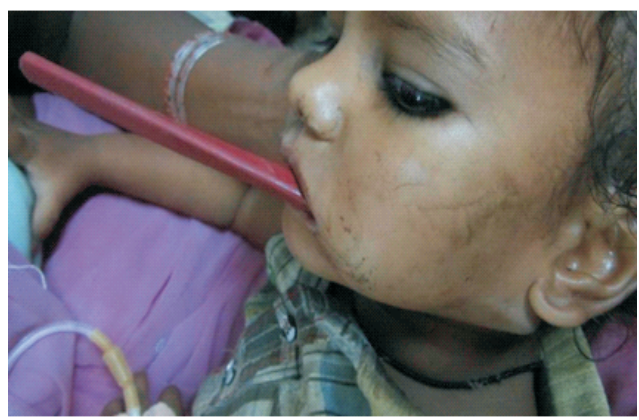

Fig 1. Patient at presentation in emergency

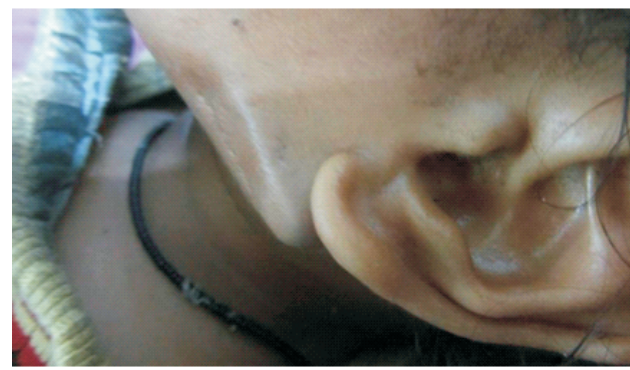

Fig 2. Detailed view of the outline of the tooth brush 


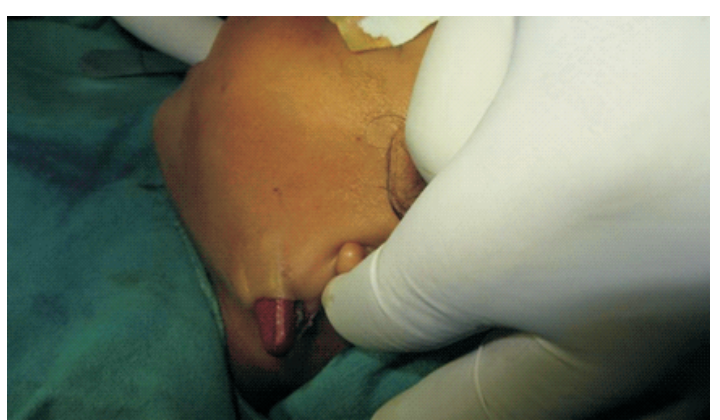

Fig 3. Incision through which the toothbrush was retrieved

\section{CONCLUSION}

Though brushing is a mandatory, self performed oral hygiene activity advocated to maintain healthy dentition and periodontal status, it can cause inadvertent trauma of the hard and soft tissues of oral cavity and surrounding structures. These trauma are more likely to be in the group which lacks manual dexterity, i.echildrens, mentally retarded individuals and the geriatric group of people.

However, considerations to prevent and improve the outcome of the trauma can always be beneficial. ${ }^{1,45}$ Supervision of children while brushing and not allowing them to run or walk with any objects in the mouth. Penetrating injuries in oral cavity should be considered potentially life threatening and the penetrated object should be removed with precaution under controlled environment. Monitoring of the patient posttraumatically as the complication of such injuries doesn't manifest at the early period and the possible complication may have a fatal outcome as well if management is delayed ${ }^{810}$

\section{REFERENCES}

1. Tse SM, Laxer RM. Approach to acute limb pain in childhood. Pediatr Rev. 2006;27:1709.

2. Attarian DE. Septic sacroitiitis: the overlooked diagnosis. J South Orthop Assoc. 2001;10:5760.

3. Ford LS, Ellis AM, Allen HW, Campbell DE. Osteomyelitis and pyogenic sacroiliitis: A difficult diagnosis. J Paediatr Child Health. 2004;40:3179.

4. U. B. Schaad, G. H. McCracken, and J. D. Nelson, "Pyogenic arthritis of the sacroiliac joint in pediatric patients," Pediatrics. 1980;66(3):375379.

5. G. T. Abbott and H. Carty, "Pyogenic sacroiliitis, the missed diagnosis?"British Journal of Radiology. 1993;66(782) : 120122.

6. Sahaad UB, McCracken GH, Jr., Nelson JD. Pyogenic arthritis of the sacroiliac joint in pediatric patients.Pediatr. 1980;66:3759.
7. M. S. Wu, S. S. Chang, S. H. Lee, and C. C. Lee, "Pyogenic sacroiliitisa comparison between paediatric and adult patients," Rheumatology. 2007;46(11):16841687

8. A. Wada, K. Takamura, T. Fujii, H. Yanagida, and P. Surijamorn, "Septic sacroiliitis in children," Journal of Pediatric Orthopaedics. 2008;28(4):488492.

9. A. Molinos Quintana, B. Morillo Gutiérrez, M. S. Camacho Lovillo, O. Neth, and I. Obando Santaella, "Pyogenic sacroiliitis in childrena diagnostic challenge," Clinical Rheumatology. 2011;30(1):107113.

10. Feldman LS. Salmonella septic sacroiliitis: case report and review. Pediatr Infect Dis J. 2006;25:1879.

11. Ariza J, Pujol M, Valverde J, et al. Brucellar sacroiliitis: findings in 63 episodes and current relevance. Clin Infect Dis. $1993 ; 16: 7615$.

12. Pourbagher A, Pourbagher MA, Savas L, et al. Epidemiologic, clinical, and imaging findings in brucellosis patients with osteoarticular involvement. Am J Roentgenol. 2006;187:87380.

13. Aprin H, Turen C. Pyogenic sacroiliitis in children. Clinl Orthop Relat Res. 1993:98106.

14. A. A. Osman and S. Govender, "Septic sacroiliitis," Clinical Orthopaedics and Related Research. 1995;313:214219.

15 J. J. Vyskocil, M. A. McIlroy, T. A. Brennan, and F. M. Wilson, "Pyogenic infection of the sacroiliac joint. Case reports and review of the literature,"Medicine. 1991;70(3):188197.

16. Ncube BA. Pyogenic sacroiliitis in children. Br J Clin Pract. 1988;42:1547.

17. R. Raman, H. Dinopoulos, and P. V. Giannoudis, "Management of pyogenic sacroilitis: an update,"Current Orthopaedics. 2004;18(4):321325.

18. Doita M, Yoshiya S, Nabeshima Y, et al. Acute pyogenic sacroiliitis without predisposing conditions.Spine.2003;28 E3849.

19. Moyer RA, Bross JE, Harrington TM. Pyogenic sacroiliitis in a rural population. J Rheumatol.1990;17:13648. [PubMed]

20. Hodgson BF. Pyogenic sacroiliac joint infection. Clin Orthop Relat Res. 1989:1469.

21. M. Grippi, L. E. Zionts, E. R. Ahlmann, D. M. Forrester, and M. J. Patzakis, "The early diagnosis of sacroiliac joint infections in children," Journal of Pediatric Orthopaedics.2006;26(5) :589593. 